\title{
Drug Release Study on Chitosan Carbon Dot Loaded Chitosan Polymer Film for Wound Healing and Drug Delivery
}

\author{
Ranju Kandra*, and Sunil Bajpai \\ Department of Chemistry, Polymer Research Laboratory, Govt. Model Science College, Jabalpur, India
}

*Corresponding author: Ranju Kandra, Department of Chemistry, Polymer Research Laboratory, Govt. Model Science College, Jabalpur, India, E-mail: kandraranju@gmail.com

Received: 18 Apr, 2020 | Accepted: 15 May, 2020 | Published: 22 May, 2020

Citation: Kandra R, Bajpai S (2020) Drug Release Study on Chitosan Carbon Dot Loaded Chitosan Polymer Film for Wound Healing and Drug Delivery. J Drug Res Dev 6(1): dx.doi.org/10.16966/2470-1009.152

Copyright: (c) 2020 Kandra R, et al. This is an open-access article distributed under the terms of the Creative Commons Attribution License, which permits unrestricted use, distribution, and reproduction in any medium, provided the original author and source are credited.

\begin{abstract}
In this study, antibacterial drug Oxy tetracycline (OTC) was loaded in to carbon dots (CNPs)/chitosan (Ch) nanocomposite films for controlled release in wound healing management. The OTC loaded CDs/Ch films were characterized by FTIR, XRD, SEM and AFM analysis. The kinetic drug release experiments were also carried out. It was found that samples $\mathrm{Ch} / \mathrm{CD}(0) 800, \mathrm{Ch} / \mathrm{CD}(2)_{800}, \mathrm{Ch} / \mathrm{CD}(4)_{800}$ and $\mathrm{Ch} / \mathrm{CD}(7)_{800}$ released a total amount of $645,488,359$ and $187 \mu \mathrm{mol}$ per g film respectively in a total duration of $8 \mathrm{~h}$. Out of Power Function Model and Schott Model, applied on the kinetic drug release data, the Schott model was better fitted. The ' $n$ ' values, obtained for the samples $\mathrm{Ch} / \mathrm{CD}(0)_{800}$, $\mathrm{Ch} / \mathrm{CD}(2)_{800}$, Ch/CD (4) $)_{800}$ and Ch/CD $(7)_{800}$ were $0.35,0.45,0.47$ and 0.49 respectively, thus indicating a Fickian type drug release mechanism. It was also found that $M \infty$ values obtained for various samples were in close agreement with those predicted by Schott model. The TS showed an interesting trend, being maximum (11.7 $\mathrm{MPa}$ ) or plain chitosan film sample $\mathrm{Ch} / \mathrm{CD}(0)$. The TS of CDs-loaded chitosan films were comparatively much smaller. Finally, the films showed fair antibacterial activities against the model bacteria E. Coli and virus staphylococcusas studied by method of Zone of Inhibition.
\end{abstract}

Keywords: Carbon dots; Chitosan; Wound healing; Drug release

\section{Introduction}

Since their discovery in 2004, carbon dots have emerged out as a new class of material with a number of attractive physicochemical properties like fluorescence [1] fair water solubility [2] non-toxicity [3] biocompatibility [4], chemical stability [5] etc. Owing to these excellent properties, carbon dots (CDs) have potential to be used in bio-imaging [6-7] bio sensing [8-10], drug delivery [11-15] catalysis [16-19] etc. Recently, we have reported water absorption and moisture permeation behaviour of chitosan/carbon dots nanocomposite films [20-21] and observed that carbon dots act as an effective cross linker due to electrostatic interactions between negatively charged carboxylate groups on the surface of carbon dots and positively charged - $\mathrm{NH} 3$ + groups along the protonated chitosan chains. It was observed that water absorption of chitosan/carbon dots nanocomposite films decreased many folds as compared to the plain chitosan films. This led us to believe that incorporation of carbon dots into drug-loaded chitosan film could bring about a desirable release of entrapped bioactive ingredient in a controlled manner. Chitosan is a semi-synthetic polymer, obtained from a controlled de-acetylation of chitin [22] .Because of excellent biocompatibility; chitosan has a wide range of biomedical applications [23]. Since carbon dots also possess fair biocompatibility, a combination of pre-calculated quantities of chitosan and carbon dots could serve as an effective dressing material to offer a controlled release of drug in wound healing management. In the present work, we have prepared carbon dots from 1,2,3,4 Butane tetra carboxylic acid via microwave synthesis approach. The CDs, so prepared, had their surface covered with - $\mathrm{COOH}$ groups. Then we entrapped these functionalized CDs along with model antibacterial drug Oxy tetracycline (OTC) in chitosan film by solution casting method. The release of drug OTC from the film matrix could be regulated by varying the CDs concentration within the film matrix as CDs provided physical cross linking to the chitosan network. Therefore, variation in the CDs contents within the film matrix could regulate the release rate of OTC. In this way, without using toxic chemical cross linking agents, a controlled release of OTC from chitosan films could be achieved.

Oxytetracycline (OTC) is a product of the metabolism of Streptomyces rimosusandis one of the categories of tetracycline antibiotics. Oxytetracycline is firstly bacteriostatic and is explained to exert its antimicrobial effect by the prevention of the protein synthesis [24].

\section{Materials and Methods}

Chitosan powder, with a molar mass of $375 \mathrm{k} \mathrm{Da}$ and degree of de-acetylation of 98 percent was obtained from Sisco Research Lab, Pune, and was used as received. It is a de-acetylated product of Chitin, a natural bio-polymer, and its structure is given as below: 
The carbon resource material 1, 2, 3, 4-Butanetetracarboxylic acid (BTCA) with molar mass of 243.16 was purchased from E. Merck, Mumbai, India and was A R grade. The model drug Oxy tetracycline (OTC) was purchased from a local medical store (HS CODE30042042). All the solutions were prepared in the distilled water and the same was used to prepare simulating wound fluid (SWF).Glacial acetic acid and other chemicals obtained from Merck, Mumbai, India. (Figure 1)

\section{Synthesis of carbon dots from BTCA}

CDs were prepared by microwave assisted synthesis as described in our previous report [25]. In brief, a pre-calculated quantity of BTCA was dissolved in distilled water and was exposed to microwave radiations (LG, model No.CE1041DFB, USA) for definite time periods. After that, the concentrated solution was diluted to a total volume of $25 \mathrm{ml}$, followed by mild stirring and sonication (UV Tech Sonicator, India). The so formed black carbonized powder of organic source BTCA was cooled to room temperature and stored in a glass vial. Two different dispersion mediums, viz, ethanol and 0.1 $\mathrm{M}$ acetic acid were used in preparation of carbon dots from BTCA. Aquantity of $300 \mathrm{mg}$ of the carbonized BTCA was dispersed in $10 \mathrm{~mL}$ of the dispersion medium and kept for $24 \mathrm{~h}$. The dispersed medium was then centrifuged (at 10,000 rpm for $0.5 \mathrm{hr}$ ) and the supernatant liquid containing BTCA carbon dots was collected and preserved for further studies. The whole method has been schematically represented in figure 2 .

\section{Preparation of chitosin/carbon dots (Ch/CDs) nanocomposite films}

The films were prepared by solvent evaporation method as described elsewhere. A 2 percent chitosan solution $(\mathrm{w} / \mathrm{v})$ was prepared in 1 percent $(\mathrm{v} / \mathrm{v})$ glacial acetic acid medium under mild stirring for a period of $1 \mathrm{hr}$ so as to ensure complete dissolution of polymer to give a semi-transparent pale yellow solution. Chitosan-carbon nano nanocomposite films were pre-pared by the similar solution technique followed for chitosan composites films. We have preferably chosen carbon dots prepared by dispersing in $0.1 \mathrm{M}$ acetic acid for synthesizing chitosan-carbon dots composites films keeping in mind the fact that chitosan is soluble in acetic acid. The resulting solutions were then mechanically stirred at room temperature for $2 \mathrm{hr}$ followed by neutralization of the system by adding $5 \mathrm{~N} \mathrm{NaOH}$. The composites films were then washed with Millipore water for several times to remove unreacted monomers and casted on glass plates followed by drying at $60^{\circ} \mathrm{C}$. The dried films were peeled off by wetting them with water and stored in vacuum at room temperature. The four chitosanCDs nanocomposite films thus prepared from wt $\%$.BTCA CDs were named as below.

\section{Preparation of OTC-loaded $\mathrm{Ch} / \mathrm{CD}$ films}

The procedure for preparation of drug-loaded films was almost the same, with an addition that a pre-calculated quantity of drug was also added in to the film forming solution prior to their transfer into Petri plates for solvent evaporation. The films, thus prepared were designated as $\mathrm{Ch} / \mathrm{CD}(\mathrm{x})_{\mathrm{y}}$ where, the number $\mathrm{x}$ and $\mathrm{y}$ denote the volume of CDs solution (in $\mathrm{ml}$ ) and amount of drug (in $\mathrm{mg}$ ) respectively. In all, five samples were prepared whose designations were $\mathrm{Ch} / \mathrm{CD}(2)_{0}, \mathrm{CD} / \mathrm{Ch}(0)_{800}, \mathrm{CD} / \mathrm{Ch}(2)_{800}, \mathrm{CD} /$ $\mathrm{Ch}(4)_{800}$ and $\mathrm{CD} / \mathrm{Ch}(7)_{800}$ respectively. It may be noticed that first sample does not contain any drug, while second sample is the plain chitosan film with 800 micro gram of drug per $g$ film. Remaining four samples have same amount of drug within the film matrix but differ in their CDs contents.

\section{Characterization of $\mathrm{Ch} / \mathrm{CD}$ films}

The film samples $\mathrm{Ch} / \mathrm{CD}(2)_{0}$ and $\mathrm{Ch} / \mathrm{CD}(2)_{80}$ were characterized for FTIR, AFM, SEM and cell cyotoxicity analysis. For FTIR analysis, the samples were grinded finely and their spectra ware recorded on a Shimadzu, 8201 PC Spectrophotometer using KBr pelleting method. The scans recorded were the average of 100 scans and the selected spectral range between, 400 to $4000 \mathrm{~cm}^{-1}$. The X-ray diffraction (XRD) method was used to measure the crystalline nature of samples using a Rikagu Diffractometer (Cu radiation, $\lambda=0.1546 \mathrm{~nm}$ ) running at 40 $\mathrm{kV}$ and $40 \mathrm{~mA}$. The scanning rate was $20 \mathrm{~s}^{-1}$ in $2 \theta$ range of 30 to $80^{\circ}$. Scanning electron microscopy (SEM) images were obtained using a Hitachi field-emission SEM (S4800, Japan) at $5 \mathrm{kV}$.

\section{Drug release study}

The drug release studies were carried out in the phosphate buffer saline of $\mathrm{pH} 7.4$ at $37^{\circ} \mathrm{C}$. In brief, a pre-weighed piece of drug loaded film was put in $50 \mathrm{ml}$ of $\mathrm{PBS}$ at $37^{\circ} \mathrm{C}$. The patch was taken out at different time intervals and absorbance of the release medium was recorded by UV-Vis spectrophotometer (Genesys, Hong Kong) at $360 \mathrm{~nm}$. The absorbance was transformed into concentration, using Lambert-Beers law, obtained with a series of standard solutions of drug TC, prepared in phosphate buffer saline of $\mathrm{pH}$ 7.4.

\section{Microbial penetration}

The microbial penetration test was carried out to access the resistance of the representative film sample $\mathrm{CD} / \mathrm{Ch}(2)_{20}$ against microorganism. For this, $5 \mathrm{ml}$ of Brain heart infusion (BHI) broth culture medium was placed in a $10 \mathrm{ml}$ vial (test area $0.8 \mathrm{~cm}^{2}$ ) and the vial was capped with the sample $\mathrm{CD} / \mathrm{Ch}(2)_{20}$ and kept at ambient temperature. We measured bacterial growth measured on $3^{\text {rd }}$ and $7^{\text {th }}$ day. The negative control was bottle covered with cotton balls while an open vial served as positive control. The turbidity, as an indication of microbial contamination, was measured at $600 \mathrm{~nm}$ using micro plate spectrophotometer.

\section{Results and Discussion}

\section{Preparation of $\mathrm{Ch} / \mathrm{CD}(\mathrm{x})_{\mathrm{y}}$ films}

In this work, $\mathrm{Ch} / \mathrm{CDs}$ nanocomposite films were prepared by solvent casting method, which is a well-established route to prepare nanocomposite materials [26]. When aqueous solution of $\mathrm{CD}$ is mixed in to chitosan solution under vigorous stirring, carbon dots are dispersed uniformly in the chitosan solution. As the carbon dots possess negatively charged carboxylate groups on their surface, their

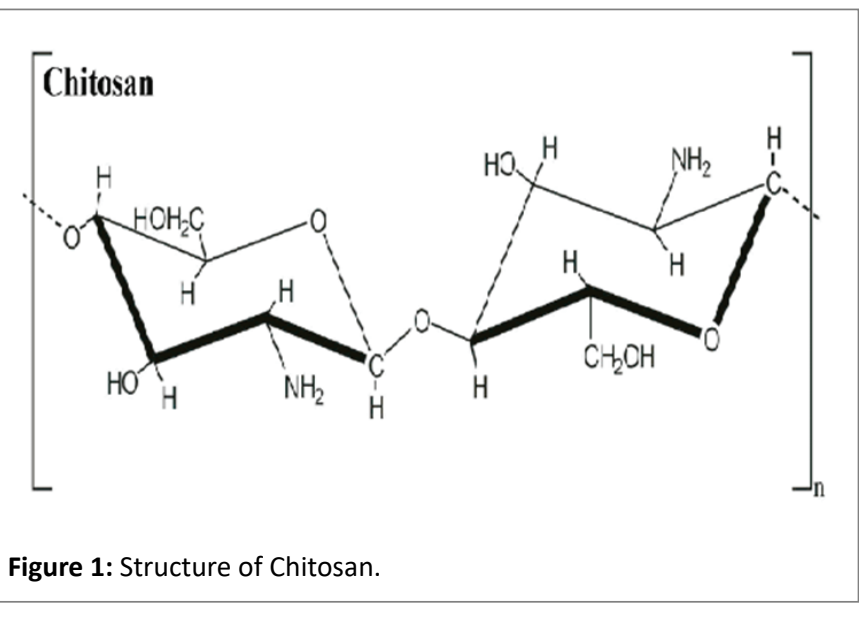


surface carries negative charge as was also confirmed by the zeta potential value of $-12.6 \mathrm{mV}$. Now, these negatively charged carbon dot are electrostatically attracted towards positively charged amino groups that are present along the chitosan chains. In this way, these protonated amino groups act as templates for carbon dots and hence they are uniformly distributed throughout the film matrix. The whole scheme of formation of $\mathrm{Ch} / \mathrm{CD}$ composite film is well shown in figure 3.

\section{Characterization of $\mathrm{Ch} / \mathrm{CD}$ nanocomposites films}

The FTIR spectra of plain chitosan film and CD loaded chitosan film are shown in figure $4 \mathrm{a}$ and $\mathrm{b}$ respectively. It can be seen in figure 4(a) that the stretching vibrations of $-\mathrm{OH}$ bond lies at $3635.94 \mathrm{~cm}^{-1}$ and that for $\mathrm{C}-\mathrm{H}$ is observed at $2954.08 \mathrm{~cm}^{-1}$. The absorption peaks at $1652.09 \mathrm{~cm}^{-1}, 1539.25 \mathrm{~cm}^{-1}, 1458.23 \mathrm{~cm}^{-1}, 1336.71 \mathrm{~cm}^{-1}$ are associated with the presence of the $\mathrm{C}=\mathrm{O}$ stretching of the amide $\mathrm{l}$ band, bending vibrations of the N-H ( $\mathrm{N}$ acetylated residues amide II band), C-H bending, and $\mathrm{OH}$ bending respectively. The peak at $1167.94 \mathrm{~cm}^{-1}$ is assigned to anti-symmetric stretching of (C-O-C) bridge, $1075.33 \mathrm{~cm}$ ${ }^{1}$ were anticipated to the skeleton vibration involving $\mathrm{C}-\mathrm{O}$ stretching.

The presence of drug OTC molecules loaded into the chitosan polymer was indicated by FTIR spectrum shown in figure 4(b). The functional group of OTC drug shows a sharp peak at $3578.07 \mathrm{~cm}^{-1}$. The FTIR spectra of dissolved OTC indicate that the shape and relative intensity peaks at $1699.34 \mathrm{~cm}^{-1}, 1559.50 \mathrm{~cm}^{-1}, 1458.23 \mathrm{~cm}^{-1}, 1336.71 \mathrm{~cm}^{-1}$ $1280.52 \mathrm{~cm}^{-1}$ were associated with the presence of the $\mathrm{C}=\mathrm{O}$ stretching of the amide 1 band, bending vibrations of the $\mathrm{N}-\mathrm{H}(\mathrm{N}$ acetylated residues amide $\mathrm{II}$ band), $\mathrm{C}-\mathrm{H}$ bending, $\mathrm{OH}-1$ bending respectively. A peak at $1559-1699 \mathrm{~cm}^{-1}$ was ascribed to the deformation of amide moieties and $1458 \mathrm{~cm}^{-1}$ ascribed to the phenol groups.

\section{SEM characterization}

The SEM images of the drug loaded samples $\mathrm{Ch} / \mathrm{CD}(2)_{800}$ and plain film Ch/CD (2) (without drug OTC) are shown in figure 5a,b, and c respectively. It is worth noticing here that the former sample contains drug OTC whereas the later sample does not contain OTC. It can be seen in figure $5 \mathrm{a}$, and $\mathrm{b}$, obtained at 2000 and $4000 \mathrm{X}$ magnifications, that the surface texture of drug loaded sample $\mathrm{Ch} / \mathrm{CD}(2)_{800}$ is quite rough and uneven. This may probably be attributed to the fact that drug OTC has poor solubility in water and therefore its dispersion in the film forming solution imparted roughness to the film texture due to its precipitation throughout the film matrix. Moreover, the image, shown in figure 5(b), obtained with 4000X magnifications, indicates that some cracks are also present on the surface. It appears
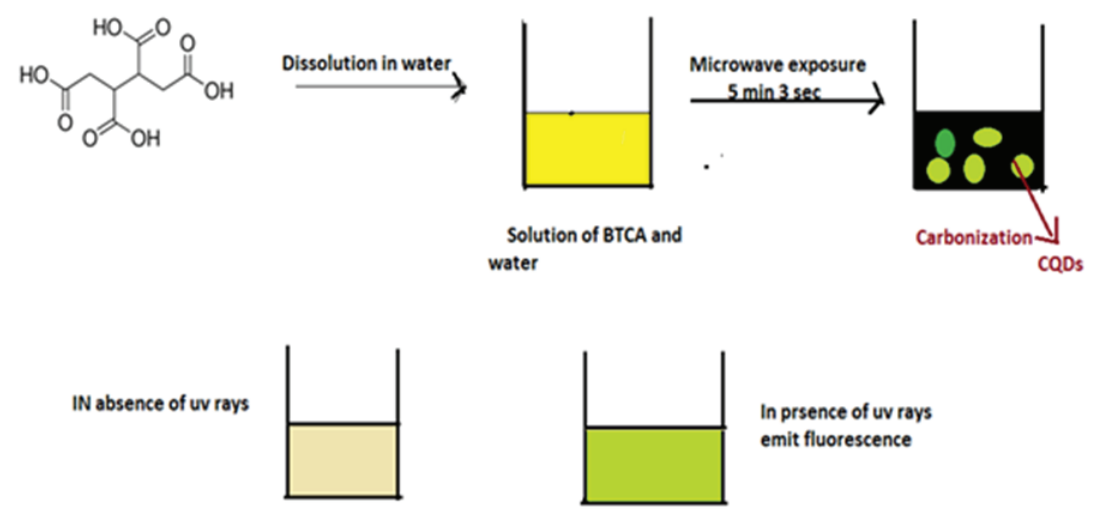

Figure 2: Synthesis of CD from Organic Source BTCA.

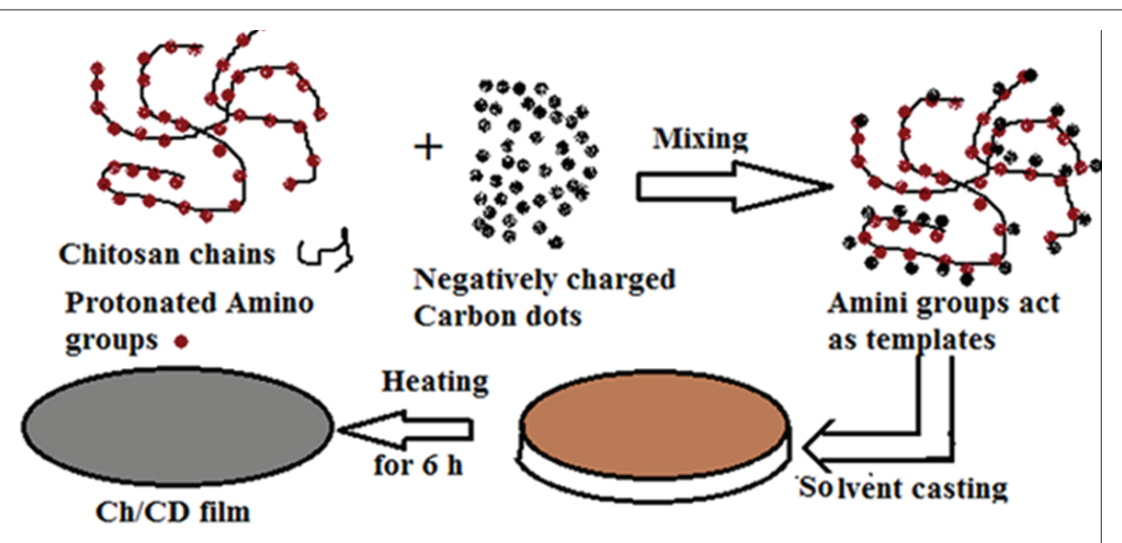

Figure 3: Schematic formation Ch/CD Films. 


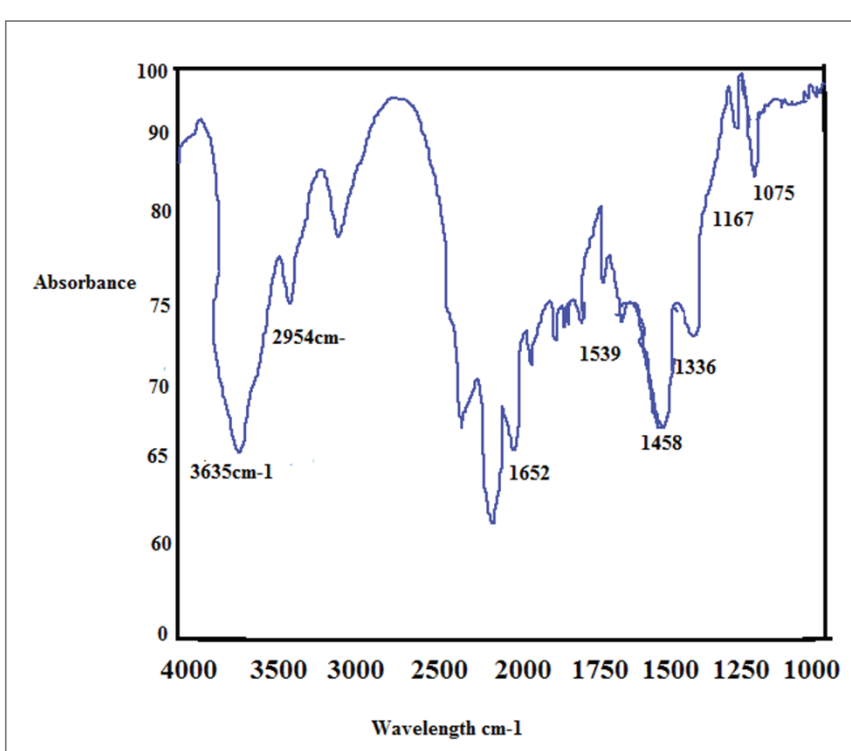

Figure 4a: FT-IR Spectrum of Ch/CD OTC drug loaded film.

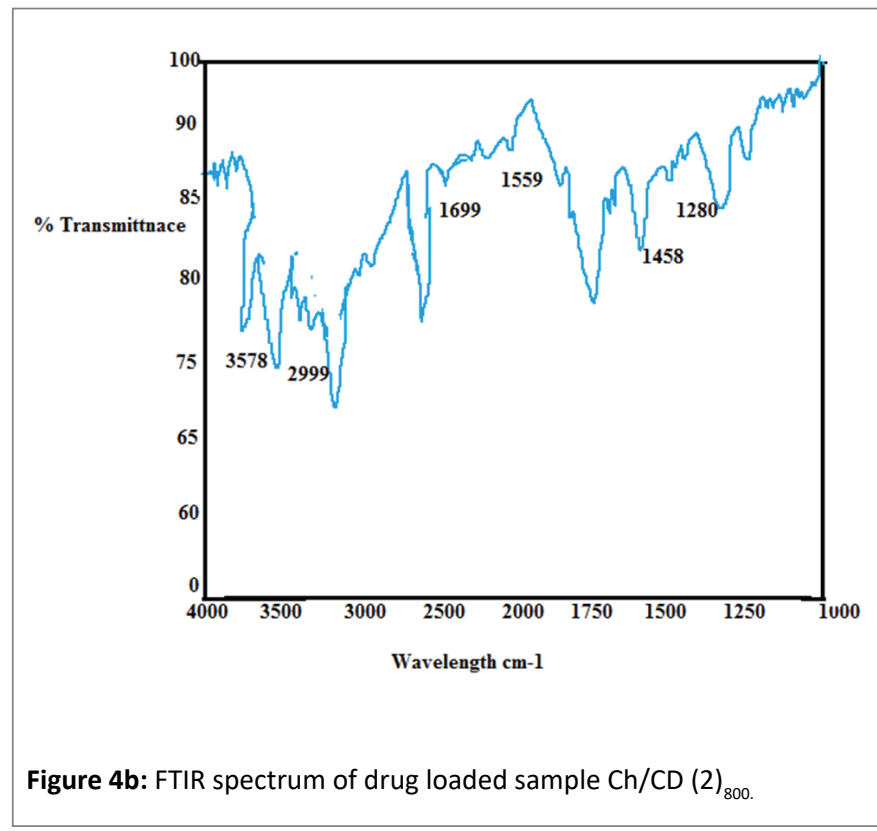

that films might have been dried at relatively higher temperature. Finally, the SEM image of the sample Ch/CD (2), obtained at 1000X magnifications, reveals relatively smooth texture of the film surface, definitely due to the absence of drug OTC in the film matrix. However, some agglomerations are also visible, might possibly be due to the presence of some particles of undissolved chitosan.

\section{Tensile strength (TS) of chitosan and chitosan-carbon dots loaded nanocomposites films}

Mechanical properties of the both the films were studied determining their tensile strength (TS) following standard ASTM D882-91 procedure. The testing was done on Universal Testing Machine using a $100 \mathrm{Kg}$ load cell at a speed of $10 \mathrm{~mm} / \mathrm{min}$. TS was measured in MPa unit which denotes the maximum force $(\mathrm{N})$ per unit cross sectional area $\left(\mathrm{mm}^{2}\right)$ required to break the sample and $\mathrm{E}$, given here, is the percent ratio of the length of the sample film at the maximum force to the original length.

The mechanical strength was investigated for plain chitosan film $\mathrm{Ch} /$ CD (0) and CDs loaded samples. We prepared, in all, five film samples with their designations as $\mathrm{Ch} / \mathrm{CD}(0), \mathrm{Ch} / \mathrm{CD}(4), \mathrm{Ch} / \mathrm{CD}(7)$ and $\mathrm{Ch} /$ $\mathrm{CD}$ (12) and $\mathrm{Ch} / \mathrm{CD}$ (17). Tensile strength (TS) of sample Ch/CD (0) film was found to be $11.7 \mathrm{MPa}$ as shown in figure 6. The high TS could be attributable to the strong electrostatic interactions within polar hydroxyl groups present in chitosan molecules. It is a well-reported fact that chitosan has a very excellent film forming property [27]. It may also be seen in figure 6 that as the CDs concentration within the film matrix increases, the TS of the resulting film decreases. In this way the sample $\mathrm{Ch} / \mathrm{CD}(7)$ attains a TS of $0.40 \mathrm{MPa}$. The reason may be that with the increase in the concentration of the carbon dots, some aggregation of the same in the polymer matrix might have occurred. This probably led to decrease in tensile strength of the resulting films. However, most interestingly, as the carbon dots a concentration was further increased in the samples $\mathrm{Ch} / \mathrm{CD}$ (12) and $\mathrm{Ch} / \mathrm{CD}$ (17), the TS began to rise. It appears that at such a high concentrations of $-\mathrm{COOH}$ functionalized carbon dots within the film matrix, the electrostatic attractive forces between - $\mathrm{COOH}$ groups present on the surface of $\mathrm{CDs}$ and protonated amino groups - $\mathrm{NH} 3$ + along the chitosan chains become predominant and cause an increase in the TS of resulting films Therefore, a very interesting trends was observed within the CDs loaded chitosan films. (Table 1)

\section{AFM characterization}

Atomic force microscopy (AFM) was used to examine the surface structure of self-assembled films obtained from water-soluble chitosan rich solution precursor. The film was supported onto functionalized glass slides resulting in a mountain-and-valley structure. This feature is attributed as resulting of the experimental condition where agglomeration of molecules in solution may occur. The film height does not exceed $20 \mathrm{~nm}$ with medium pore size of approximately 12 $\mathrm{nm}$. This range of porosity is suitable for nanofiltration applications. A comparative depiction of AFM images of plain figure 7(b) and carbon dots loaded films figure 7 (a) reveals that plain film has a relatively much smoother surface with some crack that could be due to the folding of the film at the micron level. However, the surface of the film, loaded with carbon dots, exhibits a rough texture with a number of grooves of micrometer size. It appears that carbon dots must have been agglomerated on the surface unevenly the below figure $7 \mathrm{a}$ and $\mathrm{b}$ shows the AFM images of plain.

\section{Drug release studies}

Effect of CDs contents on drug release: As discussed in our previous work, carbon dots, present within the film matrix, acted as effective cross linker due to oppositely charged interactions. As a result, presence of CDs caused a severe decrease in the water absorption capacity of the nanocomposite films. Therefore we expected almost similar trend in

Table 1: Mechanical properties of Ch/CD composites films.

\begin{tabular}{|c|c|c|}
\hline S. No & Sample Name & Ultimate stress (MPa) \\
\hline 1 & $\mathrm{Ch} / \mathrm{CD}(0)$ & 11.7 \\
\hline 2 & $\mathrm{Ch} / \mathrm{CD}(4)$ & 2.5 \\
\hline 3 & $\mathrm{Ch} / \mathrm{CD}(7)$ & 0.4 \\
\hline 4 & $\mathrm{Ch} / \mathrm{CD}(12)$ & 0.83 \\
\hline 5 & $\mathrm{Ch} / \mathrm{CD}(17)$ & 4.82 \\
\hline
\end{tabular}




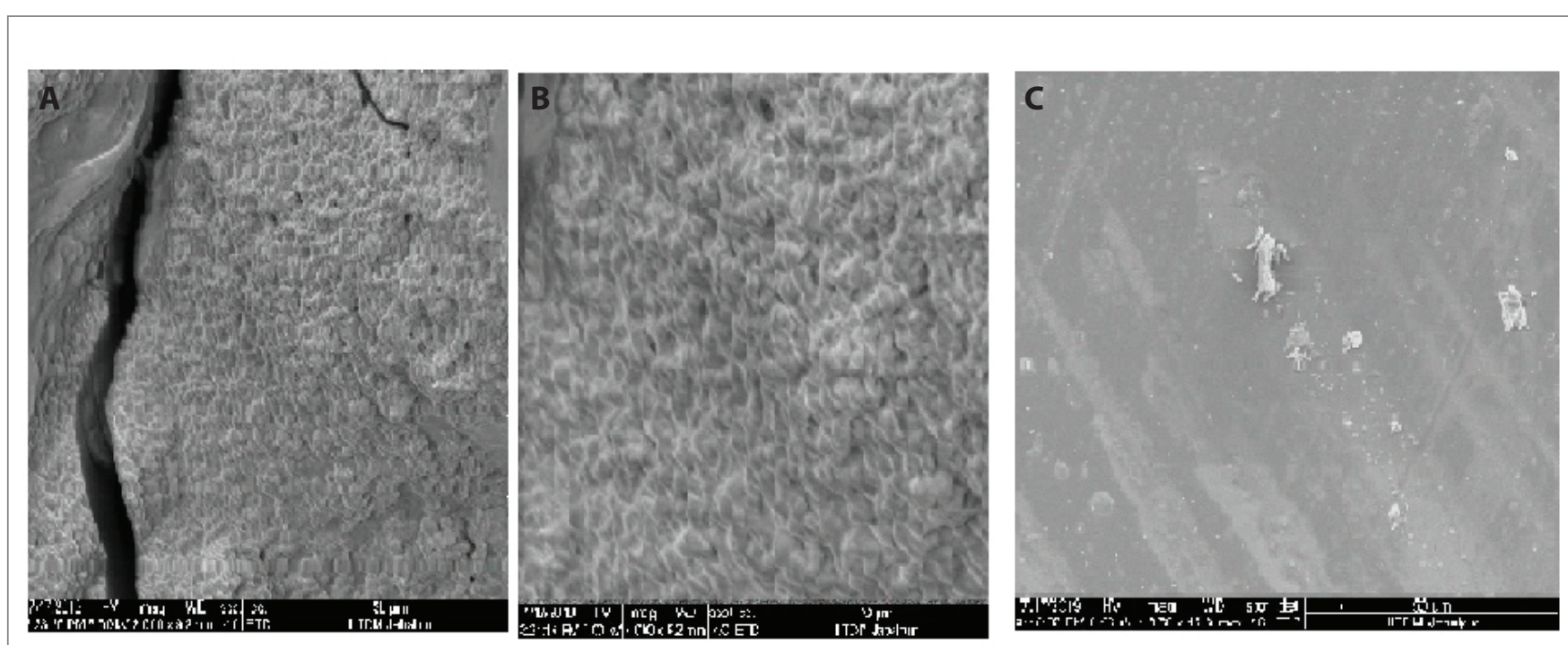

Figure 5: SEM images of drug loaded sample Ch/CD (2) ${ }_{800}$ at (a) 2000X, (b) $4000 \mathrm{X}$ and Sample Ch/CD (2) at 1000X Magnifications.

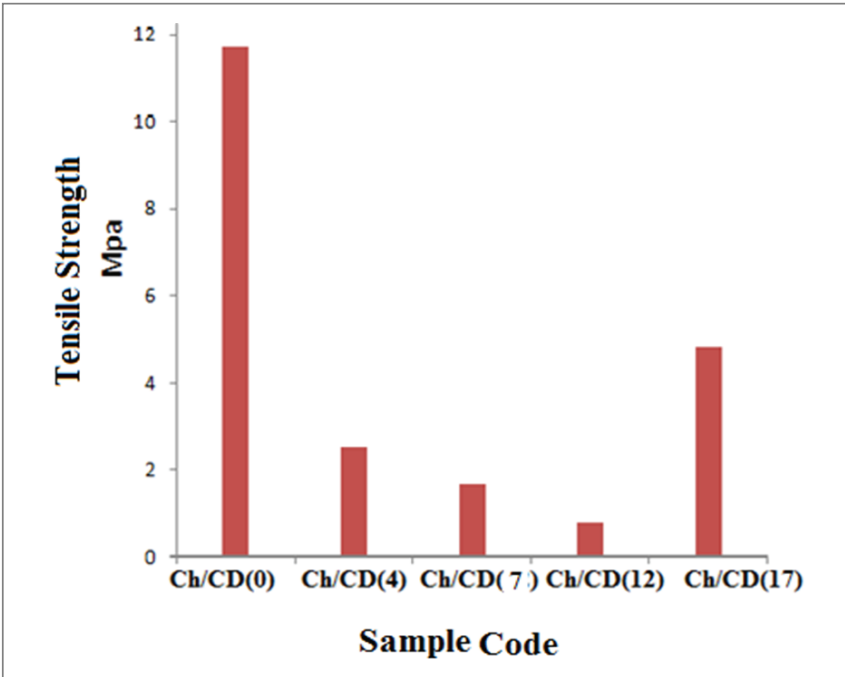

Figure 6: Mechanical properties of $\mathrm{Ch} / \mathrm{CD}$ nanocomposites films.

the case of drug release from the OTC-loaded nanocomposite films. To test this, film samples $\mathrm{Ch} / \mathrm{CD}(0)_{800}, \mathrm{Ch} / \mathrm{CD}(2)_{800}, \mathrm{Ch} / \mathrm{CD}(4)_{800}$ and $\mathrm{Ch} / \mathrm{CD}(7)_{800}$ were immersed in phosphate buffer saline of $\mathrm{pH} 7.4$ and the release was monitored spectrophotometrically at different time intervals (Figure 8). The results are shown in figure 8. It may be noticed that (i) the sample $\mathrm{Ch} / \mathrm{CD}(0)_{800}$, which does not contain carbon dots, exhibits highest release while the samples $\mathrm{Ch} / \mathrm{CD}(2)_{800}, \mathrm{Ch} / \mathrm{CD}(4)_{800}$ and $\mathrm{Ch} / \mathrm{CD}(7)_{800}$ show a decreasing trend. It was found that samples $\mathrm{Ch} / \mathrm{CD}(0)_{800}, \mathrm{Ch} / \mathrm{CD}(2)_{800}, \mathrm{Ch} / \mathrm{CD}(4)_{20}$ and $\mathrm{Ch} / \mathrm{CD}(7)_{800}$ released a total amount of $645,488,359$ and $187 \mu$ mol per $\mathrm{g}$ film respectively in a total duration of $8 \mathrm{hr}$.

The results could be interpreted in the terms of increased cross linking within the film matrices with increasing CDs content. Firstly, the sample $\mathrm{Ch} / \mathrm{CD}(0)_{800}$ (without $\mathrm{CDs}$ in matrix) offers a fastest drug release, because there are no additional electrostatic cross links present in the film.
However, the other three samples, namely $\mathrm{CD} / \mathrm{Ch}(2)_{800}, \mathrm{CD} /$ $\mathrm{Ch}(4)_{800}$ and $\mathrm{Ch} / \mathrm{CD}(7)_{800}$ show a decreasing trend. It appears that electrostatic cross links between the protonated amino groups of chitosan chains and negatively charged carboxylate groups on the surfaces of CDs act as a barrier for incoming drug molecules, offering them less space for accommodation. These results are in agreement with our previous findings related to water absorption behaviour for the same samples.

Kinetic modelling of release data: The kinetic release data was interpreted by 'Power function model' [28] According to which the fractional release is given as:

$$
\mathrm{F}=\mathrm{M}_{\mathrm{t}} / \mathrm{M} \infty=\mathrm{kt}^{\mathrm{n}} . .(4.1)
$$

Where, $\mathrm{F}(\mathrm{Mt} / \mathrm{M} \infty)$ is the fractional release at time't'; ' $\mathrm{n}$ ' and ' $\mathrm{k}$ ' are release exponent and gel characteristic constants respectively. The values of release exponent ' $n$ ' decides the nature of release pattern, whether Fickian or non-Fickian [29]. Using the logarithmic form of Eq.(1), i.e. $\ln F=\ln k+n \ln t$, plots were obtained between $\ln F$ and $\ln$ $t$ (Figure 9) below which were straight lines with fair regressions, thus indicating the suitability of the model on release data. A close look reveals that the regressions are quite higher for all the four samples studied. The ' $n$ ' values, obtained from the slopes of the linear plots for the samples $\mathrm{Ch} / \mathrm{CD}(0)_{800}, \mathrm{Ch} / \mathrm{CD}(2)_{800^{\circ}}, \mathrm{Ch} / \mathrm{CD}(4)_{800}$ and $\mathrm{Ch} / \mathrm{CD}$ $(7)_{800}$ were $0.35,0.45,0.47$ and 0.49 respectively. As these all values are below 0.5 , this suggests that the release of OTC from the film samples is totally diffusion controlled, thus following the Fickian diffusion mechanism. As for as the samples Ch/CD (2) ${ }_{800}, \mathrm{Ch} / \mathrm{CD}(4)_{800}$ and Ch/ $\mathrm{CD}(7)_{800}$ are concerned, the presence of carbon dots within the film matrices produces additional cross links via electrostatic interactions as discussed in the previous section. Therefore relaxation of polymeric chitosan chains is totally restricted and the drug comes out of the film in simply diffusion controlled manner. Moreover, the sample $\mathrm{Ch} / \mathrm{CD}$ (0) also shows Fickian release mechanism, though it does not contain carbon dots within the matrix. This is attributable to the fact that as the release medium is alkaline, i.e. $\mathrm{pH}$ 7.4, the protonated chitosan chains undergo de-protonation and acquire neutral charges along their networks. Therefore, relaxation of macromolecular chains does not occur to an appreciable extent and drug is released in a simple 

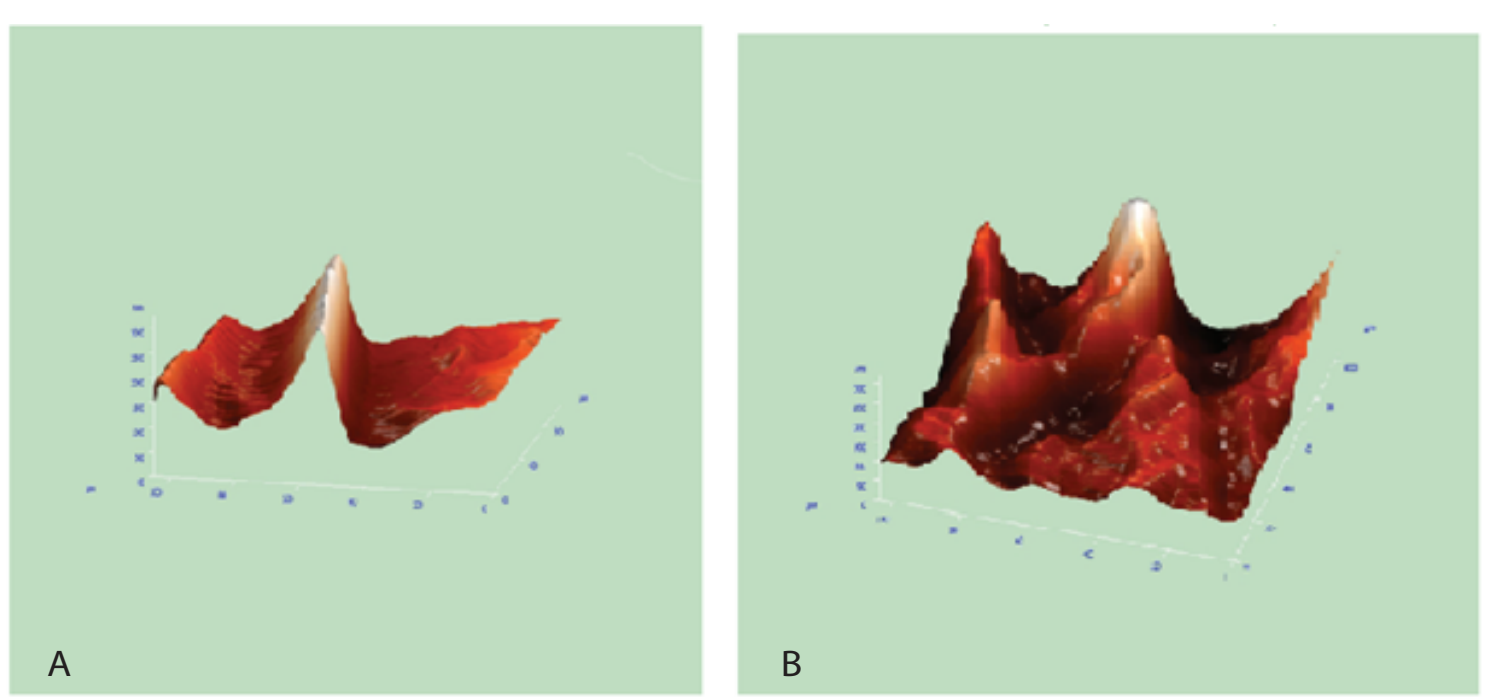

Figure 7 (A) And (B): AFM images of plain Chitosan and carbon dot loaded Chitosan film.
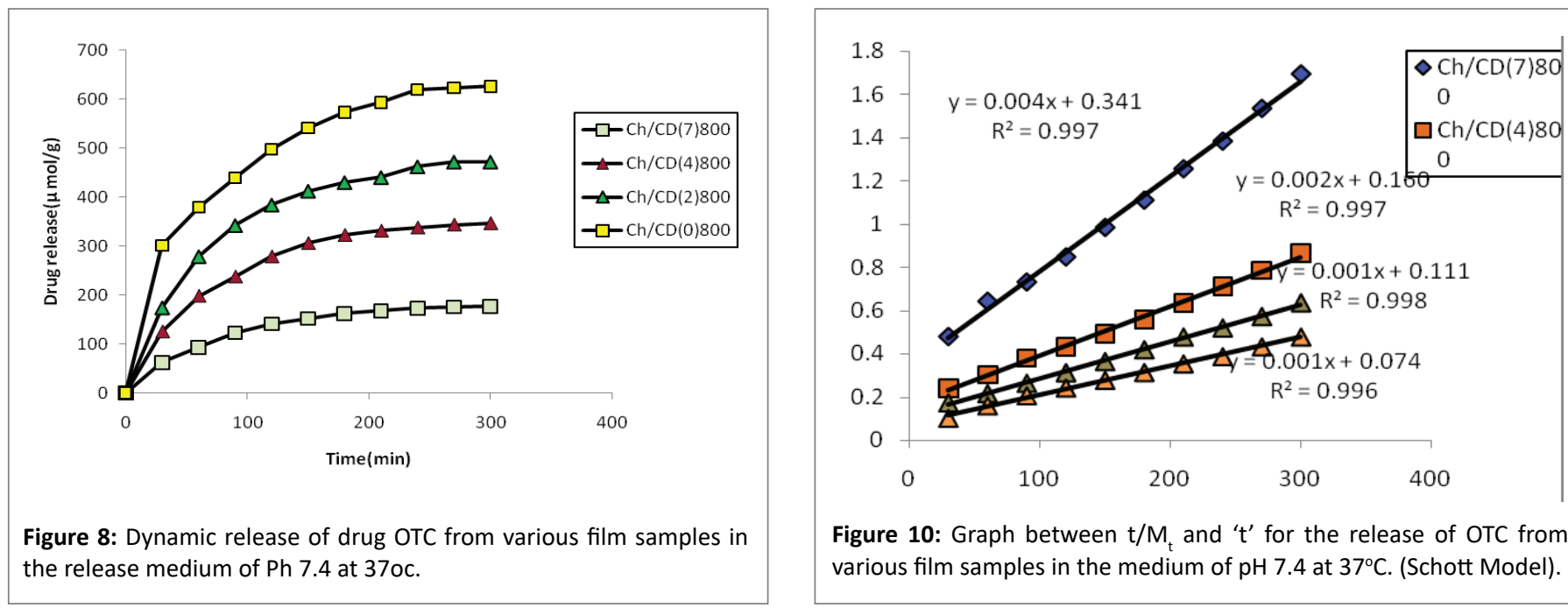

Figure 10: Graph between $t / M_{t}$ and ' $t$ ' for the release of OTC from various film samples in the medium of $\mathrm{pH} 7.4$ at $37^{\circ} \mathrm{C}$. (Schott Model).

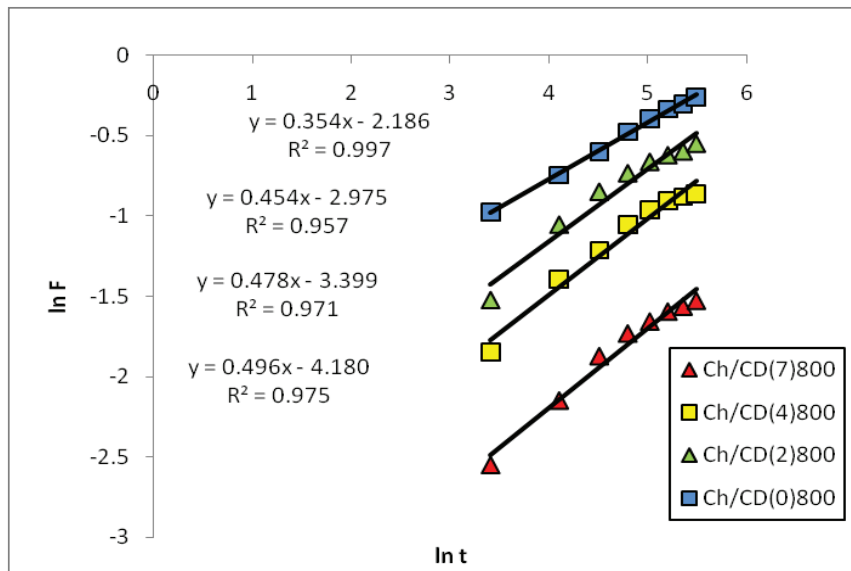

Figure 9: Power function model for OTC release from various $\mathrm{Ch} / \mathrm{CD}$ film samples in the medium of $\mathrm{Ph} 7.4$ at 37 oc.

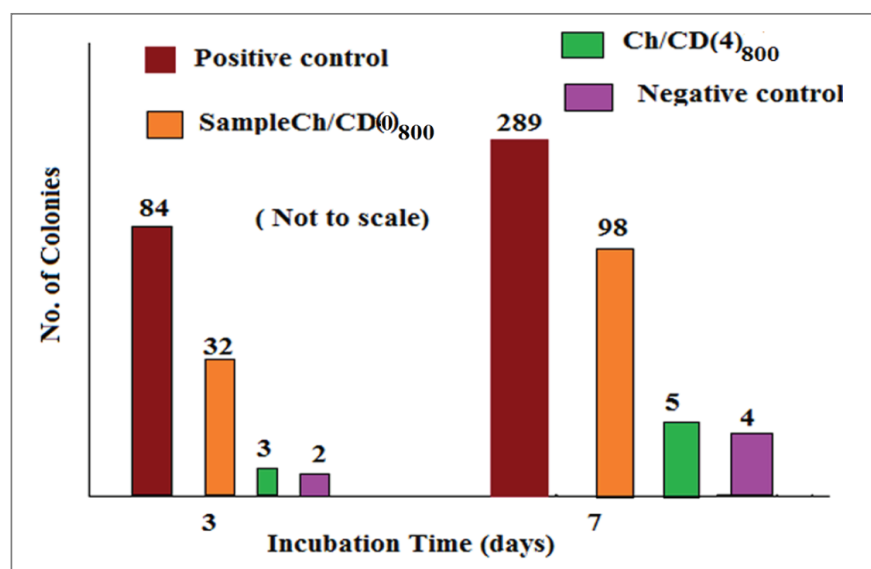

Figure 11: Microbial invasion of the film samples $\mathrm{Ch} / \mathrm{CD}(0)_{800}$ and $\mathrm{Ch} / \mathrm{CD}(4)_{800}$. 


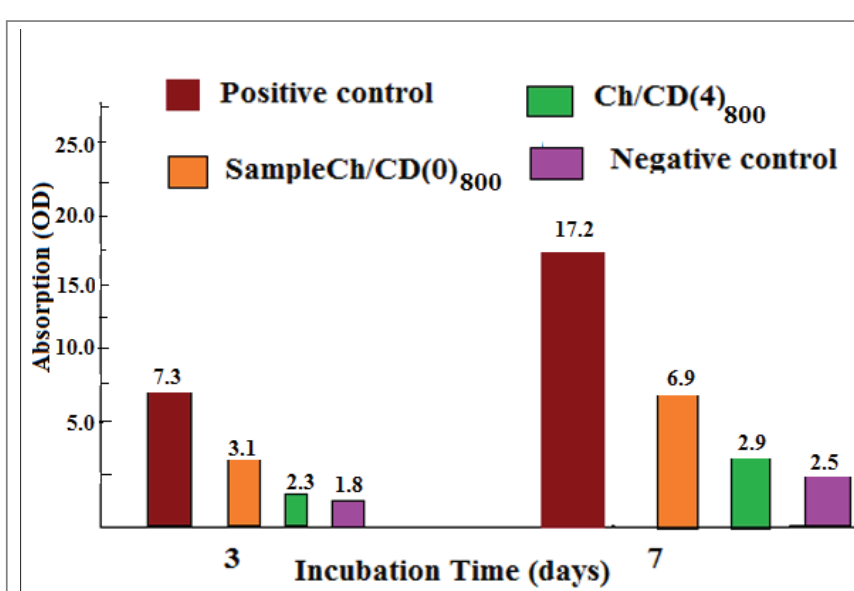

Figure 12: Microbial invasion of the film samples $\mathrm{Ch} / \mathrm{CD}(0)_{800}$ and $\mathrm{Ch} /$ $\mathrm{CD}(4)_{800^{\circ}}$

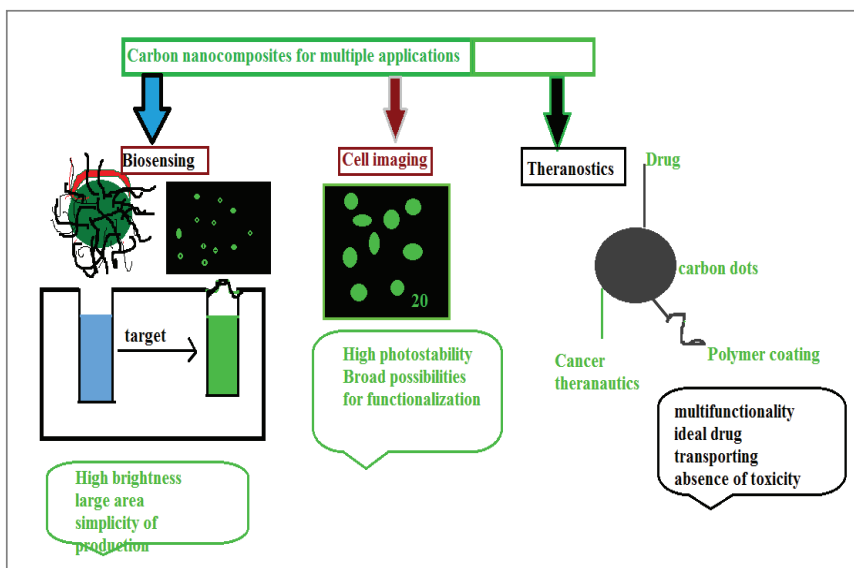

Figure 13: Graphical abstract

diffusion controlled manner. The total drug, released from all the four samples, namely Ch/CD (0) ${ }_{800}, \mathrm{Ch} / \mathrm{CD}(2)_{800}, \mathrm{Ch} / \mathrm{CD}(4)_{800}$ and Ch/CD (7) $)_{800}$ was found to $645,488,359$ and $187 \mu$ mol per g film respectively in a total time period of $8 \mathrm{hr}$.

As the Power function model is only applicable for the $60 \%$ release data, we also applied the kinetic data on the Schott model which is based on the presumption that rate of drug release at any time ' $t$ ' is proportional to the quadratic of the quantity of drug released before the equilibrium is attained .According to this model,

$$
\mathrm{dM}_{\mathrm{t}} / \mathrm{d}_{\mathrm{t}}=\mathrm{k}_{2}\left(\mathrm{M}_{\mathrm{t}}-\mathrm{M}_{\infty}\right)^{2} \ldots
$$

Where ' $k_{2}$ is the second order rate constant, Mt and $M \infty$ are the amounts of drug released at time ' $\mathrm{t}$ ' and at equilibrium respectively. Integration of Eq. (4.2) yields:

$$
\mathrm{t} / \mathrm{M}_{\mathrm{t}}=1 /\left(\mathrm{k}_{2} \times \mathrm{M}_{\infty}^{2}\right)+\mathrm{t} / \mathrm{M}_{\infty}
$$

The $t / M t$ values were plotted against ' $t$ ' as shown in figure 10 and the slopes and intercepts of linear plots were used to calculate the rate constant $\mathrm{k}_{2}$ and theoretical $\mathrm{M} \infty$ (theor) i.e. the maximum quantity of drug that could be released as per Schott model. It may be noticed that the regression values obtained are quite higher as compared to those obtained with Power function model.

All the parameters associated with the above two models, namely Power function model and Schott model are given in table 2. It is

\begin{tabular}{|c|c|c|c|c|c|c|c|}
\hline \multirow[b]{2}{*}{ Sample } & \multicolumn{5}{|c|}{ Power Function Model } & \multicolumn{2}{|c|}{ Schott Model } \\
\hline & $\mathbf{R}^{2}$ & $\mathbf{n}$ & $\mathrm{k} \times 10^{3}$ & $\mathbf{R}^{2}$ & $k_{2} \times 10^{5}$ & $\begin{array}{l}M_{\infty(\text { theor) }} \\
\mu \mathrm{mol} / \mathrm{g}\end{array}$ & $\begin{array}{r}M_{\infty}(\exp ) \\
\mu \mathrm{mol} / \mathrm{g}\end{array}$ \\
\hline $\mathrm{Ch} / \mathrm{CD}(0)_{800}$ & 0.9975 & 0.35 & 1.34 & 0.9965 & .67 & 769.3 & 772.7 \\
\hline $\mathrm{Ch} / \mathrm{CD}(2)_{800}$ & 0.9576 & 0.45 & 1.68 & 0.9987 & 3.28 & 588.2 & 592.5 \\
\hline $\mathrm{Ch} / \mathrm{CD}(4)_{800}$ & 0.9719 & 0.47 & 2.03 & 0.9972 & 2.58 & 434.7 & 430.1 \\
\hline $\mathrm{Ch} / \mathrm{CD}(7)_{800}$ & 0.9757 & 0.49 & 2.18 & 0.9971 & 2.28 & 227.2 & 223.7 \\
\hline
\end{tabular}

Table 2: Parameters associated with different kinetic models.

worth noticing here that for all the four samples, $M \infty_{\text {(theor) }}$ values are quite close to the experimental total release $M \infty_{(\exp )}$, thus suggesting better suitability of this model as compared to the former one. This is also supported by higher regressions obtained for the Schott model. (Table 2)

Microbial penetration: One of the most desirable requirements of a wound dressing film is that it must be capable to resist the microbial invasion through the dressing material and hence show a microbial barrier property. The results of microbial invasion, as shown in figure 11, indicate that out of the film samples $\mathrm{Ch} / \mathrm{CD}(0)_{800}$ and $\mathrm{Ch} /$ CD $(4)_{800}$, later is more effective in preventing bacterial transitions indicated by negligible growth of colonies in the culture media while a significant growth was observed in positive control. On $3^{\text {rd }}$ and $7^{\text {th }}$ day, the numbers of colonies in positive control were 84.68 and 289.41 respectively. However, on both of the days, the negative control and the film sample $\mathrm{Ch} / \mathrm{CD}(4)_{800}$ showed fever number of colonies, while the sample $\mathrm{Ch} / \mathrm{CD}$ (4)0 showed around 32.29 and 98.81colonies respectively. The reason is that the sample without drug, i.e. $\mathrm{Ch} / \mathrm{CD}$ (4) 0 contains chitosan as a basic antimicrobial material and therefore it shows better antibacterial action as compared to the positive sample, but is less effective than the drug loaded sample Ch/CD (4)800 due to high antibacterial action of loaded drug OTC. In addition, we also evaluated cloudiness of the nutrient broth spectrophotometrically at $600 \mathrm{~nm}$. The results, as shown in figure 12 and 13, also supported our finding that the sample $\mathrm{Ch} / \mathrm{CD}(4)_{800}$ demonstrated fair microbial barrier property as compared to the sample $\mathrm{Ch} / \mathrm{CD}(0)_{800}$. In this way it may be concluded that the sample $\mathrm{Ch} / \mathrm{CD}(4)_{800}$ has potential to be used as wound healing material.

\section{Conclusion}

It may be concluded from the above study that chitosan films, loaded with antibacterial drug OTC, can be employed for a controlled delivery of drug under physiological environment. The most significant aspect of this study lies in the fact by entrapment of functionalized carbon dots within the chitosan film, it can be cross linked physically for the controlled delivery of bioactive ingredient OTC as per requirements. Generally, chitosan is used for wound healing applications and to regulate the drug release rate, chitosan is cross linked with Glutaraldehyde, formaldehyde, Glyoxal etc. However, these cross linking agents are toxic. This work offers an alternative of these toxic chemicals. Indeed the chitosan film can be cross linked to a desired degree by loading it with functionalized carbon dots. The proposed CDs-loaded chitosan film has potential for use in wound healing management.

\section{References}

1. Namdari P, Negahdari B, Eatemadi A (2017) Synthesis, properties and biomedical applications of carbon-based quantum dots: An updated review. Biomed Pharmacother 87: 209-222. 
2. Li J, Li P, Wang D, Dong C (2019) One-pot synthesis of aqueous soluble and organic soluble carbon dots and their multi-functional applications. Talanta 202: 375-383.

3. Gyulai G, Ouanzi F, Bertóti I, Mohai M, Kolonits T, et al. (2019) Chemical structure and in vitro cellular uptake of luminescent carbon quantum dots prepared by solvothermal and microwave assisted techniques. J Colloid Interface Sci 549: 150-161.

4. Das T, Saikia BK, Dekaboruah HP, Bordoloi M, Neog D, et al. (2019) Blue-fluorescent and biocompatible carbon dots derived from abundant low-quality coals. J Photochem Photobiol B 195: 1-11.

5. Xia J, Chen S, Zou GY, Yu YL, Wang JH (2018) Synthesis of highly stable red-emissive carbon polymer dots by modulated polymerization from the mechanism to application in intracellular $\mathrm{pH}$ imaging. Nanoscale 10: 22484-22492.

6. Ahn J, Song Y, Kwon JE, Lee SH, Park KS, et al. (2019) Food wastedriven $\mathrm{N}$-doped carbon dots: Applications for $\mathrm{Fe}^{3+}$ sensing and cell imaging. Mater Sci Eng C Mater Biol Appl 102: 106-112.

7. Bhatt S, Bhatt M, Kumar A, Vyas G, Gajaria T, et al. (2018) Green route for synthesis of multifunctional fluorescent carbon dots from Tulsi leaves and its application as $\mathrm{Cr}(\mathrm{VI})$ sensors, bio-imaging and patterning agents. Colloids Surf B Biointerfaces 167: 126-133.

8. Feng H, Qian Z (2018) Functional Carbon Quantum Dots: A Versatile Platform for Chemosensing and Biosensing. Chem Rec 18: 491-505.

9. Ge S, He J, Ma C, Liu J, Xi F, et al. (2019) One-step synthesis of boron-doped graphene quantum dots for fluorescent sensors and biosensor. Talanta 199: 581-589.

10. Divya KP, Karthikeyan R, Sinduja B, Anancia Grace A, John SA, et al. (2019) Carbon dots stabilized silver-lipid nano hybrids for sensitive label free DNA detection. Biosens Bioelectron 133: 48-54.

11. Feng T, Zhao Y (2019) Preparation of Responsive Carbon Dots for Anticancer Drug Delivery. Methods Mol Biol 2000: 227-234.

12. Hettiarachchi SD, Graham RM, Mintz KJ, Zhou Y, Vanni S, et al. (2019) Triple conjugated carbon dots as a nano-drug delivery model for glioblastoma brain tumors. Nanoscale 11: 6192-6205.

13. Nasrollahi F, Koh YR, Chen P, Varshosaz J, Khodadadi AA, et al. (2019) Targeting graphene quantum dots to epidermal growth factor receptor for delivery of cisplatin and cellular imaging. Mater Sci Eng C Mater Biol Appl 994: 247-257.

14. Fang J, Liu Y, Chen Y, Ouyang D, Yang G, et al. (2019) Graphene quantum dots-gated hollow mesoporous carbon nanoplatform for targeting drug delivery and synergistic chemo-photothermal therapy. Int J Nanomedicine 13: 5991-6007.

15. Hua XW, Bao YW, Wu FG (2018) Fluorescent Carbon Quantum Dots with Intrinsic Nucleolus-Targeting Capability for Nucleolus Imaging and Enhanced Cytosolic and Nuclear Drug Delivery. ACS Appl Mater Interfaces 10: 10664-10677.
16. Li C, Fan P, Liang A, Jiang Z (2019) Using Ca-doped carbon dots as catalyst to amplify signal to determine ultratrace thrombin by freelabel aptamer-SERS method. Mater Sci Eng C Mater Biol Appl 99: 1399-1406.

17. Wang Y, Chen J, Liu L, Xi X, Li Y, et al. (2019) Novel metal doped carbon quantum dots/CdS composites for efficient photocatalytic hydrogen evolution. Nanoscale 11: 1618-1625.

18. Pirsaheb M, Moradi S, Shahlaei M, Farhadian N (2018) Application of carbon dots as efficient catalyst for the green oxidation of phenol: Kinetic study of the degradation and optimization using response surface methodology. J Hazard Mater 353: 444-453.

19. Sharma S, Mehta SK, Ibhadon AO, Kansal SK (2019) Fabrication of novel carbon quantum dots modified bismuth oxide ( $\alpha-\mathrm{Bi} 2 \mathrm{O} 3 / \mathrm{C}$ dots): Material properties and catalytic applications. J Colloid Interface Sci 533: 227-237.

20. Dias AM, Braga ME, Seabra IJ, Ferreira P, Gil MH, et al; (2011) Development of natural-based wound dressings impregnated with bioactive compounds and using supercritical carbon dioxide. Int J Pharm 408: 9-19.

21. Liu $Y$, Zhou Q, Yuan $Y$, Wu $Y$ (2017) Hydrothermal synthesis of fluorescent carbon dots from sodium citrate and polyacrylamide and their highly selective detection of lead and pyrophosphate. Carbon 115: 550-560.

22. Niamsa N, Baimark Y (2009) Preparation and Characterization of Highly Flexible Chitosan Films for Use as Food Packaging. Am J Food Technol 4: 162-169.

23. Ramya R, Venkatesan J, Se Kwon, Kim KS, Sudha PN (2012) Biomedical Applications of Chitosan: An Overview. J of Bio Biomater Tissue Eng 2: 100-111.

24. Petković H, Cullum J, Hranueli D, Hunter IS, Perić- Concha N, et al. (2006) Genetics of Streptomyces rimosus, the oxytetracycline producer. Microbiol Mol Biol Rev 70: 704-728.

25. Bhuvaneshwari S, Sruthi D, Sivasubramanian V, Kalyani N, Sugunabai J (2011) Development and characterization of chitosan film. Inter J Eng Res Appl 1: 292-299.

26. Niamsa N, Baimark Y (2009) Preparation and Characterization of Highly Flexible Chitosan Films for Use as Food Packaging. Am J Food Technol 4: 162-169.

27. Park H, Guo X, Temenoff JS, Tabata Y, Caplan Al, et al. (2009) Effect of swelling ratio of injectable hydrogel composites on chondrogenic differentiation of encapsulated rabbit marrow mesenchymal stem cells in vitro. Biomacromolecules 10: 541-546.

28. Korsmeyer RW, Gurny R, Doelker E, Buri P, Peppas NA (1983) Mechanisms of solute release from porous hydrophilic polymers. Int J Pharm 15: 25-35.

29. Siepmann J, Peppas NA (2011) Higuchi equation: derivation, applications, use and misuse. Int J Pharm 418: 6-12. 